\title{
Electrodeposition of Polypyrrole Films on Aluminum from Tartrate Aqueous Solution
}

\author{
Andréa S. Liu ${ }^{a, b}$ and Maria A. S. Oliveira ${ }^{*, a}$ \\ ${ }^{a}$ Departamento de Química, Instituto Tecnológico de Aeronáutica (ITA), Pça Mal Eduardo Gomes, 50 - CTA, \\ 12228-900 São José dos Campos-SP, Brazil \\ ${ }^{b}$ Instituto de Pesquisa e Desenvolvimento (UNIVAP), Av. Shishima Hifumi, 2911, 12244-000 \\ São José dos Campos-SP, Brazil
}

\begin{abstract}
A síntese eletroquímica de filmes de polipirrol em superfícies de alumínio, em meio aquoso contendo ácido tartárico e pirrol, foi realizada através da técnica galvanostática e por voltametria cíclica. Um mecanismo que considera o crescimento de uma camada porosa de óxido de alumínio em paralelo com a eletrodeposição do filme de polipirrol foi proposto. Foi observado que quanto mais homogênea a distribuição dos poros na camada de óxido, menor a resistência oferecida para o crescimento dos filmes de polipirrol. Também foi observado que os filmes de polipirrol depositados por voltametria cíclica são menos uniformes do que aqueles formados galvanostaticamente. Filmes eletrodepositados galvanostaticamente a maiores densidades de corrente são mais propensos ao processo de superoxidação, como mostram os resultados de FTIR. Além disso, filmes de polipirrol depositados a $2,5 \mathrm{~mA} \mathrm{~cm} \mathrm{~cm}^{-2}$ apresentam um melhor desempenho na proteção de superfícies de alumínio contra corrosão.
\end{abstract}

The electrochemical synthesis of polypyrrole films on aluminum surfaces from aqueous solutions containing tartaric acid and pyrrole was performed using cyclic voltammetry and galvanostatic techniques. A mechanism that considers a porous aluminum oxide layer growing in parallel with the polymeric film explains the polypyrrole electrodeposition on aluminum surfaces. The more homogeneous the distribution of pores on the aluminum oxide layer, the smaller is the resistance offered to the polypyrrole film growth. Polypyrrole films deposited by cyclic voltammetry are much less uniform than those galvanostatically formed. Polymeric films galvanostatically deposited at higher current densities were more susceptible to overoxidation processes than those films formed at lower current densities, as demonstrated by FTIR analyses. Furthermore, films formed at low current density perform better on protecting aluminum surfaces against corrosion.

Keywords: electrodeposition, polypyrrole, tartaric acid, aluminum

\section{Introduction}

Polypyrrole (PPy) is an attractive material because of its high conductivity, environmental stability, wide range of applications (such as membranes, batteries, anticorrosion films, etc) and easy preparation from aqueous or organic media by chemical and electrochemical methods. ${ }^{1-9}$

Pyrrole electrochemical polymerization is an advantageous process on forming PPy films. The polymer is formed and deposited on the surface of the electrode in just one process, and the chemical and physical properties of the film can be controlled by the adjusting synthesis

*e-mail: dora@ita.br parameters such as current density, monomer concentration, electrolyte type, electrolyte concentration and $\mathrm{pH} .{ }^{10}$

The working electrode plays an important role in the electropolymerization of pyrrole. Since an oxidative process produces PPy films, it is important that the metallic substrate does not oxidize concurrently with the monomer. Therefore, the electropolymerization of pyrrole is generally carried out on noble metals such as platinum and gold. ${ }^{11}$ Nevertheless, electropolymerization on oxidizable metals, such as iron, zinc and copper, have been reported. ${ }^{12-18}$

Various authors have studied the electrodeposition of PPy on aluminum electrodes with different electrolytes (oxalic acid, sulfonates, nitric acid, etc). ${ }^{19-25}$ It was shown that the type of pre-treatment (polishing or galvanostatic activation), electrolyte type, and solvent (aqueous or 
organic) affect the electropolymerization process on aluminum surfaces. When PPy is electrodeposited on aluminum surfaces from aqueous solutions containing acids with low $\mathrm{pK}_{\mathrm{a}}$, the acid is incorporated into the electropolymerized PPy as a dopant. ${ }^{21}$

Aluminum surfaces coated with PPy films electrochemically formed present an $\mathrm{Al} / \mathrm{Al}_{2} \mathrm{O}_{3} / \mathrm{PPy}$ sandwich structure. The mechanism proposed to explain this structure considers that both a PPy film and a porous oxide layer $\left(\mathrm{Al}_{2} \mathrm{O}_{3}\right)$ are formed on the aluminum electrodes in aqueous solution containing pyrrole. The electrolyte content plays an important role on determining the porosity of the oxide film formed under the PPy film.

To explain the sandwich structure, at the initial stage of the electrochemical process, the growing of $\mathrm{Al}_{2} \mathrm{O}_{3}$ layer is not entirely uniform, but rather contains a number of cracks. Pyrrole electropolymerizes preferentially inside these cracks, forming electronically conducting paths (ECPs) that extends from the aluminum substrate to the surface of the growing $\mathrm{Al}_{2} \mathrm{O}_{3}$ layer. As long as the ECPs are conducting, they can assist the continuous current flow to form a PPy layer on the top of the $\mathrm{Al}_{2} \mathrm{O}_{3}$ film. ${ }^{21}$

Although tartrate medium has been used to deposit PPy on other substrates, this medium has not been used to prepare PPy films on aluminum substrates. ${ }^{26-28}$

This work presents the results of the electrodeposition of PPy on aluminum from aqueous media containing pyrrole and tartrate in different concentrations and different values of $\mathrm{pH}$. Additionally, the efficiency of PPy films to protect aluminum surfaces against corrosion was also investigated.

Table 1. Chemical composition (\%wt.) of the aluminum

\begin{tabular}{cccccccc}
\hline Element & $\%$ wt. & Element & $\%$ wt. & Element & $\%$ wt. & Element & $\%$ wt. \\
\hline $\mathrm{Al}$ & 99.89 & $\mathrm{Ni}$ & 0.004 & $\mathrm{Ga}$ & 0.0146 & $\mathrm{Na}$ & 0.0038 \\
$\mathrm{Si}$ & 0.027 & $\mathrm{Zn}$ & 0.002 & $\mathrm{~Pb}$ & 0.001 & $\mathrm{Ca}$ & 0.0007 \\
$\mathrm{Fe}$ & 0.061 & $\mathrm{Ti}$ & 0.003 & $\mathrm{P}$ & 0.0006 & $\mathrm{Zr}$ & 0.0004 \\
$\mathrm{Cr}$ & 0.002 & $\mathrm{~V}$ & 0.012 & $\mathrm{Sb}$ & 0.0001 & Others & 0.027 \\
\hline
\end{tabular}

\section{Experimental}

All electrochemical experiments were performed at room temperature in a one-compartment cell containing three electrodes. The working electrode was a $99.89 \%$ wt. aluminum, embedded in Teflon ${ }^{\circledR}$ leaving a disc-shaped exposed area of $0.53 \mathrm{~cm}^{2}$. The reference electrode was a saturated $\mathrm{Ag} / \mathrm{AgCl}, \mathrm{Cl}^{-}$electrode, and the auxiliary electrode was a platinum wire.

Before each electrochemical experiment, the aluminum surfaces were polished with emery paper (400,
600 and 1000 grades), $3 \mu \mathrm{m}$ alumina water suspension, and rinsed with distilled water.

Pyrrole (Aldrich) was distilled prior to use and the electrolytes, tartaric acid (Reagen), sodium tartrate (Vetec), sodium hydroxide (Synth) were used as received.

The anodization process of aluminum surfaces was investigated by cyclic voltammetry. The following were the electrolyte solutions used in this studies: (i) $0.2 \mathrm{~mol}$ $\mathrm{L}^{-1}$ tartaric acid ( $\mathrm{pH} 1.7$ ); (ii) $0.2 \mathrm{~mol} \mathrm{~L}^{-1}$ sodium tartrate (pH 7.8); (iii) 0.2 mol L-1 of sodium tartrate $+\mathrm{NaOH}$ ( $\mathrm{pH} 13$ ) and (iv) $0.1 \mathrm{~mol} \mathrm{~L}^{-1}$ sodium hydroxide ( $\mathrm{pH} \mathrm{13).}$ The electrolyte solutions were prepared by dissolution of the corresponding chemicals in distilled water. The voltammetric experiments were carried out by varying the electrodes potential from $-1.0 \mathrm{~V}$ up to $2.0 \mathrm{~V}$ and reverting the potential down to $-1.0 \mathrm{~V}$. The sweep rate was $5 \mathrm{mVs}^{-1}$. The influence of the electrolyte concentration in the anodization process was also investigated galvanostatically. In these studies the $\mathrm{pH}$ was 1.7 , the tartaric acid concentration was varied between 0.2 and $0.8 \mathrm{~mol} \mathrm{~L}^{-1}$ and the applied current density was $2.5 \mathrm{~mA} \mathrm{~cm}^{-2}$.

The influence of parameters such as $\mathrm{pH}$ and monomer were investigated for the electrodeposition process of PPy. These studies were performed by cyclic voltammetry and varying the electrodes potential from $-1.0 \mathrm{~V}$ up to $2.0 \mathrm{~V}$, and reverting the potential down to $-1.0 \mathrm{~V}$ at a sweep rate of $5 \mathrm{mV} \mathrm{s}^{-1}$. The following were the electrolyte solutions used to study the $\mathrm{pH}$ and monomer concentration: (i) 0.2 mol L-1 tartaric acid $(\mathrm{pH} 1.7)+0.1 \leq$ pyrrole $\leq 0.8 \mathrm{~mol} \mathrm{~L}^{-1}$; (ii) 0.2 mol L-1 sodium tartrate $(\mathrm{pH} 7.8)+0.1 \leq$ pyrrole $\leq$ $0.8 \mathrm{~mol} \mathrm{~L}^{-1}$ and (iii) $0.2 \mathrm{~mol} \mathrm{~L}^{-1}$ of sodium tartrate $(\mathrm{pH}$ was adjusted to 13 by the addition of $\mathrm{NaOH}$ ) $+0.1 \leq$ pyrrole $\leq 0.8 \mathrm{~mol} \mathrm{~L}^{-1}$. All solutions were prepared by dissolving the chemicals in distilled water.

The electrodeposition of PPy films from aqueous solutions containing $0.2 \mathrm{~mol} \mathrm{~L}{ }^{-1}$ tartaric acid $+0.5 \mathrm{~mol} \mathrm{~L}^{-1}$ pyrrole ( $\mathrm{pH}$ 1.7) was also investigated by the galvanostatic technique. The applied current densities were varied between 0.5 and $10 \mathrm{~mA} \mathrm{~cm}{ }^{-2}$.

The corrosion of aluminum surfaces just polished and polished and coated with PPy films was investigated by potentiodynamic polarization technique. The surfaces were exposed to a $0.1 \mathrm{~mol} \mathrm{~L}^{-1} \mathrm{NaCl}$ aqueous solution $(\mathrm{pH}$ 5.9), not stirred, open to the atmosphere and temperature around $25^{\circ} \mathrm{C}$. The experiments were carried out by varying the electrodes potential, at $5 \mathrm{mV} \mathrm{s}^{-1}$, from $-1.0 \mathrm{~V}$ up to $+1.0 \mathrm{~V}$ and reverting the potential down to $-1.0 \mathrm{~V}$.

The corrosion potential $\left(\mathrm{E}_{\text {corr }}\right)$ and the corrosion current densities $\left(\mathrm{j}_{\text {corr }}\right)$ values were obtained from the Tafel plots. The $\mathrm{E}_{\text {corr }}$ is the potential at which the current density is 
zero. The $j_{\text {corr }}$ was determined by extrapolation of the linear anodic and cathodic branches of the Tafel plots to $\mathrm{E}_{\text {corr }}{ }^{29}$

All the electrochemical experiments were carried out using a Potentiostat / Galvanostat MQPG-01 Model (Microquímica).

FTIR was used to analyze the PPy films composition. The spectra were obtained using a spectrometer model SPECTRUM-2000 (Perkin Elmer). The analysis conditions were: wavenumber range of $4000-400 \mathrm{~cm}^{-1}, 4$ $\mathrm{cm}^{-1}$ resolution, 40 scans, and ambient temperature (25 $\left.{ }^{\circ} \mathrm{C}\right)$. $\mathrm{KBr}$ pellets were prepared with solid tartaric acid and with the PPy films removed from aluminum surfaces.

The morphology of surfaces coated with PPy films was analyzed using a Jeol JXA-840A Scanning Electron Microscope. The micrographs were obtained using an energy electron beam of $15 \mathrm{keV}$.

\section{Results and Discussion}

Anodization of aluminum in aqueous solution containing tartrate anions in different concentration and/or $\mathrm{pH}$

Since the mechanism proposed to explain the PPy formation on aluminum surfaces considers that a porous oxide layer is formed in parallel with the polymer film, and the electrolyte has an important role in the type of oxide film (porous or barrier) developed during the anodization process, the anodic oxide film formation in tartrate solutions in various concentrations and $\mathrm{pH}$ was investigated by cyclic voltammetry and galvanostatic techniques.

The anodization curves were obtained by exposition of the aluminum electrode to aqueous media containing (1) $0.2 \mathrm{~mol} \mathrm{~L}^{-1}$ tartaric acid (pH 1.7); (2) $0.2 \mathrm{~mol} \mathrm{~L}^{-1}$ sodium tartrate (pH 7.8); (3) $0.2 \mathrm{~mol} \mathrm{~L}^{-1}$ of sodium tartrate $+\mathrm{NaOH}$ (pH 13), and (4) $0.1 \mathrm{~mol} \mathrm{~L}^{-1} \mathrm{NaOH}$ (pH 13). Figure 1 shows the cyclic voltammograms obtained in these experiments.

Each polarization curve presented in Figure 1 shows a tendency to attain a limiting current density, which increases with $\mathrm{pH}$, indicating that the aluminum dissolution increases as the hydroxyl concentration increases. These results can be ascribed to the dissolution of the aluminum oxide film due to the $\mathrm{pH}$ increase, which contributes for the decrease in the oxide layer thickness. ${ }^{30-33}$ A thinner oxide layer explains the high values of the anodic currents during the reverse potential scan for those aluminum surfaces exposed to alkaline media.

In alkaline media, the aluminum dissolution is smaller when tartrate is present in the solution (see curves 3 and 4). It is well established that during the formation of aluminum oxide in aqueous media, aluminum ions are continuously generated at the metal/oxide interface and

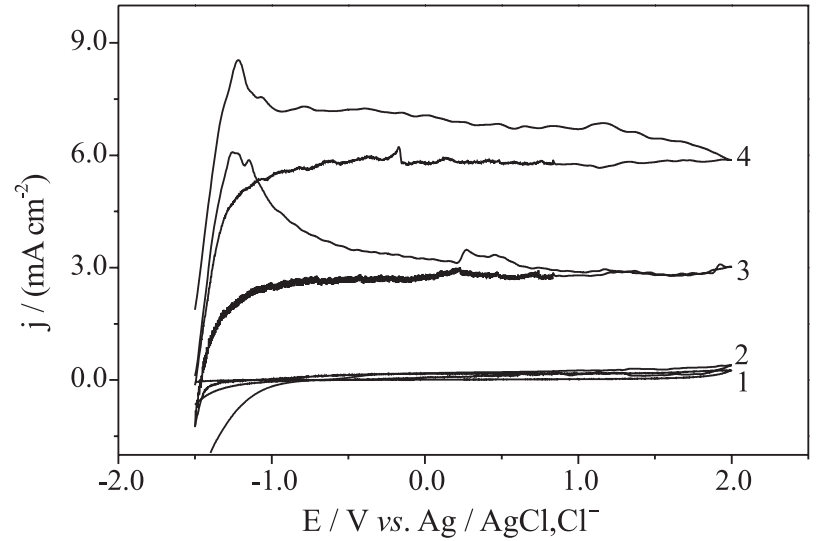

Figure 1. First-cycle voltammetry for anodization curves at $5 \mathrm{mV} \mathrm{s}^{-1}$, for aluminum exposed to: (1) $0.2 \mathrm{~mol} \mathrm{~L}^{-1}$ tartaric acid (pH 1.7); (2) $0.2 \mathrm{~mol}$ $\mathrm{L}^{-1}$ sodium tartrate $(\mathrm{pH} 7.8)$; (3) $0.2 \mathrm{~mol} \mathrm{~L}^{-1}$ of sodium tartrate $+\mathrm{NaOH}$ (pH 13), and (4) $0.1 \mathrm{~mol} \mathrm{~L}^{-1} \mathrm{NaOH}(\mathrm{pH} \mathrm{13)}$.

migrate through the growing oxide layer towards the oxide/ solution interface. At this interface the aluminum ions can react with water or other species present in aqueous solution resulting in film growth. The aluminum ions can also dissolve in solution, which involves direct injection of aluminum ions from an oxide lattice into solution, resulting in a porous anodic oxide film..$^{21,34}$

The tartrate anion is a bidentate ligand that can form complexes with aluminum ions..$^{35}$ At high values of $\mathrm{pH}$, the tartrate species in aqueous solution are almost entirely in their dissociated form, which allows the formation of stable $\mathrm{Al}$ (III)-tartrate complexes at the oxide/solution interface. When tartrate is present in the electrolytic solution, the formation of $\mathrm{Al}$ (III)-tartrate complexes at the oxide/solution interface decreases the solubility of the aluminum oxide layer and explains the lower dissolution of aluminum in alkaline solutions containing tartrate $(\mathrm{pH} 13)$.

Figure 2 shows the potential-time curves obtained during the formation of the oxide films on the aluminum electrode in 0.2 and $0.8 \mathrm{~mol} \mathrm{~L}^{-1}$ tartaric acid aqueous

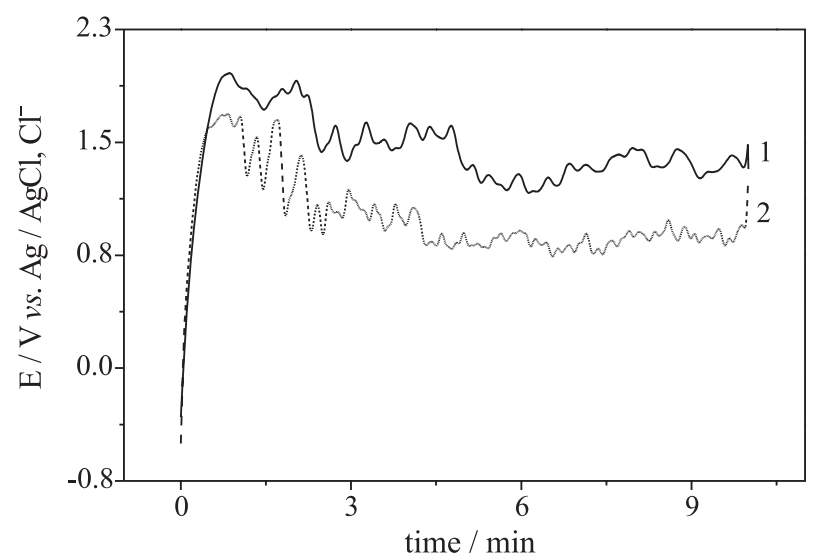

Figure 2. Transients of potential (at $2.5 \mathrm{~mA} \mathrm{~cm}^{-2}$ ) for formation of aluminum oxide film from tartaric acid solution: (1) 0.8 and (2) $0.2 \mathrm{~mol} \mathrm{~L}^{-1}$. 
solutions. The $\mathrm{pH}$ of each solution was 1.7 and the applied current density was $2.5 \mathrm{~mA} \mathrm{~cm}^{-2}$. During the galvanostatic anodization, the potential increases almost instantaneously, and after a sudden small decrease, it reaches a steady-state potential. The potential decrease during the galvanostatic anodization has been ascribed to the formation of pores on the oxide layer, due to the fieldassisted dissolution of the film in acid solutions. ${ }^{21,34}$ Potential oscillations was also observed during the galvanostatic anodization. These potential oscillations can be ascribed to an alternating dissolution and repair of passive film. This process is associated to the formation of metastable pits followed by surface repassivation. ${ }^{36,37}$

The SEM micrographs of anodic oxide films formed galvanostatically on aluminum surfaces are showed in Figure 3. The micrographs show that the oxide films formed on the aluminum surfaces are porous. The pore
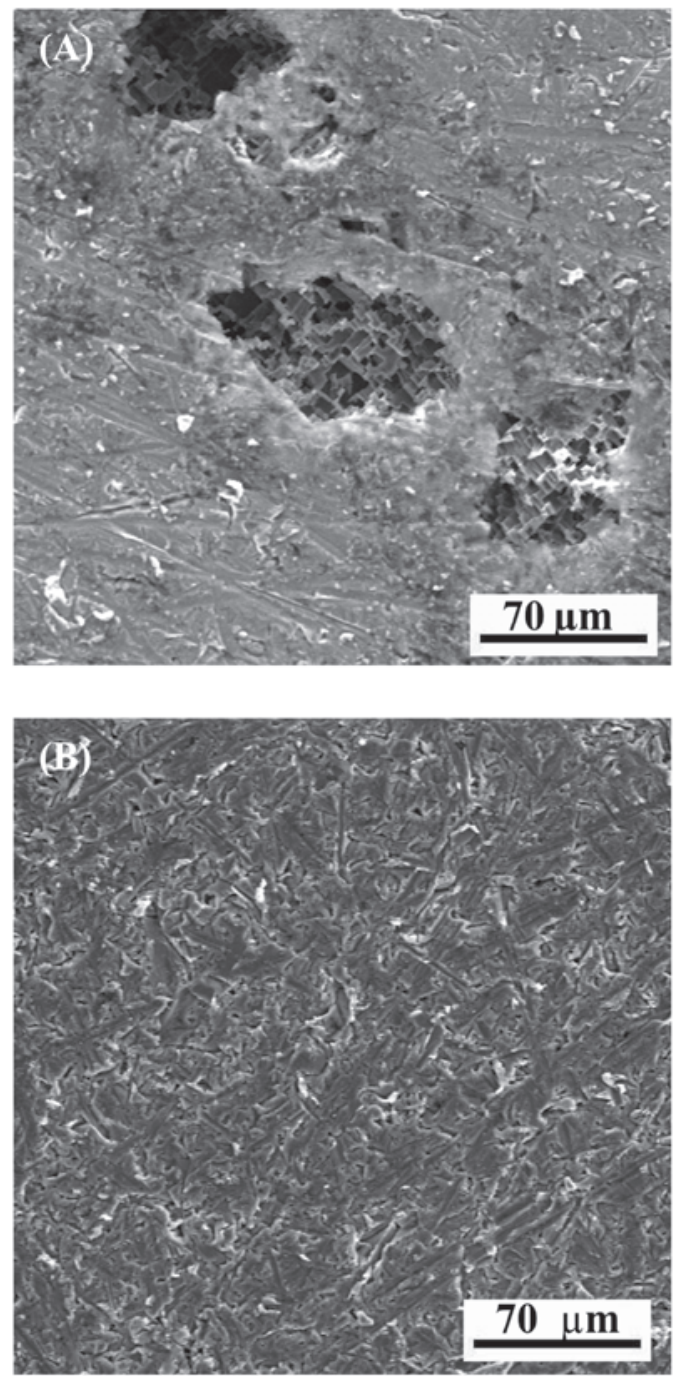

Figure 3. SEM micrograph of oxide films formed galvanostatically at $2.5 \mathrm{~mA} \mathrm{~cm}$ on aluminum exposed at tartaric acid aqueous solutions: (A) 0.2 and (B) $0.8 \mathrm{~mol} \mathrm{~L}^{-1}$. distribution is more homogeneous in oxide films formed in media containing higher tartaric acid concentration. Assuming that the film formation potential is proportional to the thickness of the anodic film, ${ }^{34}$ one can suggest that films formed in $0.8 \mathrm{~mol} \mathrm{~L}^{-1}$ tartaric acid aqueous solutions are thicker than those formed in $0.2 \mathrm{~mol} \mathrm{~L}^{-1}$.

Influence of monomer concentration on the electropolymerization of pyrrole

Figure 4 shows the results of the cyclic voltammetry experiments performed to investigate the effect of the monomer concentration on the electrodeposition of PPy. These studies were carried out in $0.2 \mathrm{~mol} \mathrm{~L}^{-1}$ tartaric acid aqueous solutions $(\mathrm{pH} 1.7)$ and varying the pyrrole concentration between 0.1 and $0.8 \mathrm{~mol} \mathrm{~L}^{-1}$.

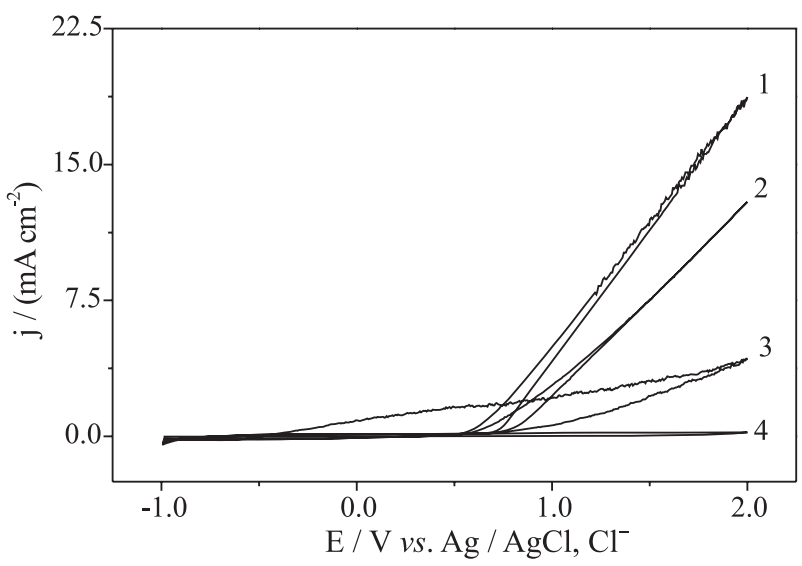

Figure 4. Voltammetric profiles (first cycle) of PPy growth in $0.2 \mathrm{~mol} \mathrm{~L}^{-1}$ tartaric acid medium and pyrrole concentrations of: (1) 0.8 , (2) 0.5 , (3) 0.2 and (4) $0.1 \mathrm{~mol} \mathrm{~L}^{-1}$. Sweep rate $5 \mathrm{mV} \mathrm{s}^{-1}$.

The formation of PPy was visually observed only when the monomer concentration was equal or greater than 0.2 mol L-1. In this last case, a black, homogeneous and thick PPy film was electrodeposited on aluminum. The results in Figure 4 also show that the potential at which the electropolymerization commences decreased slightly with increasing monomer concentration. This behaviour may be associated with diffusion process of the pyrrole on the electrode surface, which increases with monomer concentration. ${ }^{10}$ The higher the monomer concentration is, the faster the oxidation reaction of pyrrole at the interface aluminum / electrolyte solution, and the lower the potential at which the electropolymerization starts.

\section{Influence of $\mathrm{pH}$ on the electropolymerization of pyrrole}

The influence of solution $\mathrm{pH}$ on the electrodeposition of PPy on the aluminum was also investigated by cyclic 
voltammetry. For each value of $\mathrm{pH}(1.7,7.8$ and 13$)$ the pyrrole concentration was varied over the range of 0.1 to $0.8 \mathrm{~mol} \mathrm{~L}^{-1}$, while the electrolyte concentration was kept at $0.2 \mathrm{~mol} \mathrm{~L}^{-1}$. Some of the obtained voltammograms are shown in Figure 5.

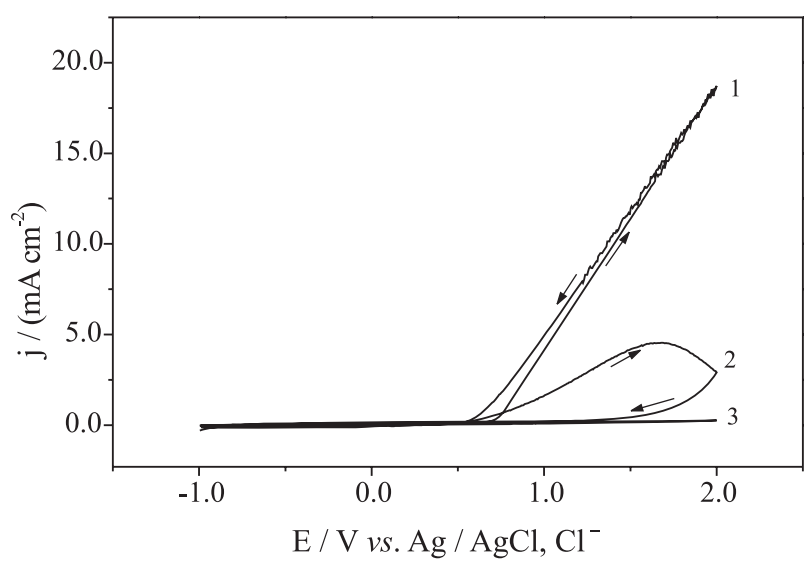

Figure 5. Voltammetric profiles (first cycle) for the electrodeposition of PPy from aqueous solutions of $0.8 \mathrm{~mol} \mathrm{~L}^{-1}$ pyrrole in: (1) $0.2 \mathrm{~mol} \mathrm{~L}^{-1}$ tartaric acid (pH 1.7); (2) $0.2 \mathrm{~mol} \mathrm{~L}^{-1}$ sodium tartrate (pH 7.8) and (3) $0.2 \mathrm{~mol}$ $\mathrm{L}^{-1}$ sodium tartrate + sodium hydroxide $(\mathrm{pH} 13)$. Sweep rate of $5 \mathrm{mV} \mathrm{s}^{-1}$.

It was observed that the electrodeposition of PPy on aluminum from tartrate containing aqueous solutions depends on the solution $\mathrm{pH}$. In acid medium, the polymer formation could be detected when the monomer concentration was equal or higher than $0.2 \mathrm{~mol} \mathrm{~L}^{-1}$. In almost neutral medium, the PPy electrodeposition only occurred when the pyrrole concentration was $0.8 \mathrm{~mol} \mathrm{~L}^{-1}$. On the other hand, PPy was not deposited in alkaline medium, even when a high pyrrole concentration $(0.8 \mathrm{~mol}$ $\left.\mathrm{L}^{-1}\right)$ was used.

Under almost neutral conditions, the growth of a thick and passive oxide film on aluminum surfaces difficult the electropolymerization process. ${ }^{38}$ In this case, the deposition of PPy occurs only in sparingly localized spots. The voltammogram for the potentiodynamic electrodeposition of PPy on aluminum in almost neutral solution (curve 2 in Figure 5) also shows an anodic current density peak at $1.7 \mathrm{~V}$. In this voltammogram, the current density values observed in the forward direction is higher than those observed in the backward scan. These last two features are typical of overoxidation of PPy, a irreversible degradation process of the polymer. ${ }^{39}$

In alkaline medium, the dissolution of the metal inhibits the oxidation of monomer and the formation of the polymeric film is not observed in this case.

The results obtained in this work show that, unlikely some results presented in literature for the electrodeposition of PPy films on cupper or zinc surfaces from tartrate aqueous solution, ${ }^{26,27}$ PPy films electrodeposited potentiodynamically on aluminum in neutral medium are not uniform.

Differently from the results presented in literature for the electrodeposition of PPy on aluminum from alkaline medium ( $\mathrm{pH}$ 12) containing nitrate or surfactants, ${ }^{39,40}$ our studies also showed that the electrodeposition of PPy in alkaline medium containing tartrate was not possible.

Influence of tartaric acid concentration on the electropolymerization of pyrrole

To get more information about the role of the tartaric acid in the electrodeposition process of PPy on aluminum, the influence of tartaric acid concentration was investigated over the concentration range of 0.1 to 0.8 mol L-1. The pyrrole concentration was fixed at $0.5 \mathrm{~mol}$ $\mathrm{L}^{-1}$ and the $\mathrm{pH}$ of each solution was adjusted to 2.0 by the addition of $\mathrm{NaOH}$. The results are shown in Figure 6.

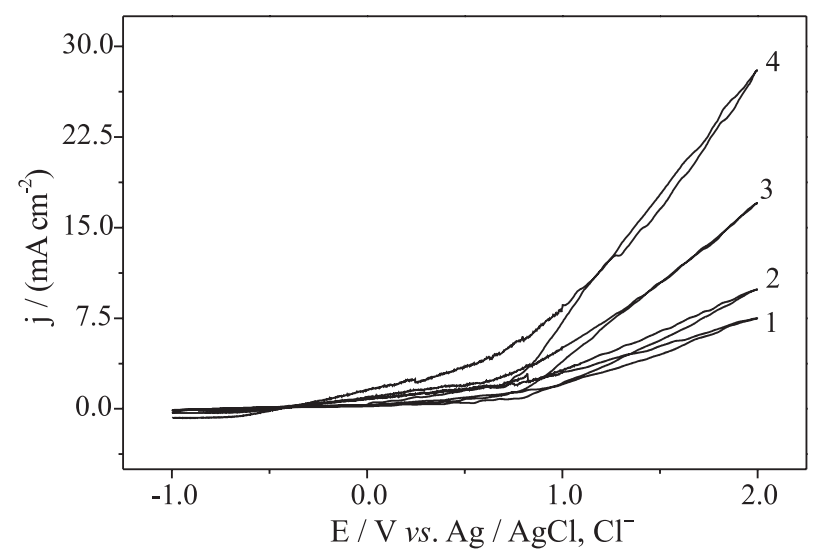

Figure 6. Voltammetric profiles (first cycle), for the electrodeposition of PPy from $0.5 \mathrm{~mol} \mathrm{~L}^{-1}$ pyrrole aqueous solutions and tartaric acid concentrations of: (4) $0.8 \mathrm{~mol} \mathrm{~L}^{-1}$, (3) $0.4 \mathrm{~mol} \mathrm{~L}^{-1}$, (2) $0.2 \mathrm{~mol} \mathrm{~L}^{-1}$ and (1) $0.1 \mathrm{~mol}$ $\mathrm{L}^{-1}$. Sweep rate $5 \mathrm{mV} \mathrm{s}^{-1}$.

The current densities of PPy formation increase as the tartaric acid concentration increases. The potential at that the electropolymerization starts gradually decrease as the electrolyte concentration increases. This effect was attributed to the overall system resistance reduction due to the electrolyte concentration increase and also to the characteristics of the aluminum oxide film formed during the anodization process. As showed previously, the pore distribution on the oxide layer formed on aluminum surfaces in media containing higher tartaric acid concentration is more homogeneous than that of the oxide layer formed in media containing lower tartaric acid concentration (Figure 3).

Considering the mechanism proposed to explain the PPy film growth on aluminum surfaces, ${ }^{21}$ via formation of conducting paths of PPy through the aluminum oxide layer 
produced at the initial stage of the PPy electropolymerization process, it seems reasonable to consider that the better the pore distribution on the aluminum oxide layer, the smaller is the resistance to the PPy film growth. The more homogeneous is the pore distribution on the aluminum oxide layer, the closer should be the PPy conducting paths formed in this oxide layer, the smaller should be the resistance for conducting paths to coalesce and spread on the electrode surface. These assumptions justify the higher amount of PPy electrodeposited on aluminum surfaces in medium containing higher tartaric acid concentration.

\section{Galvanostatic deposition of PPy films on aluminum}

Electrodeposition of PPy on aluminum was also carried out galvanostatically, at current densities values varying between 0.5 and $10 \mathrm{~mA} \mathrm{~cm}^{-2}$. The electrolytic solution used was a $0.2 \mathrm{~mol} \mathrm{~L}^{-1}$ tartaric acid $+0.5 \mathrm{~mol} \mathrm{~L}^{-1}$ pyrrole, $\mathrm{pH} 1.7$. Figure 7 shows the results obtained in these experiments.

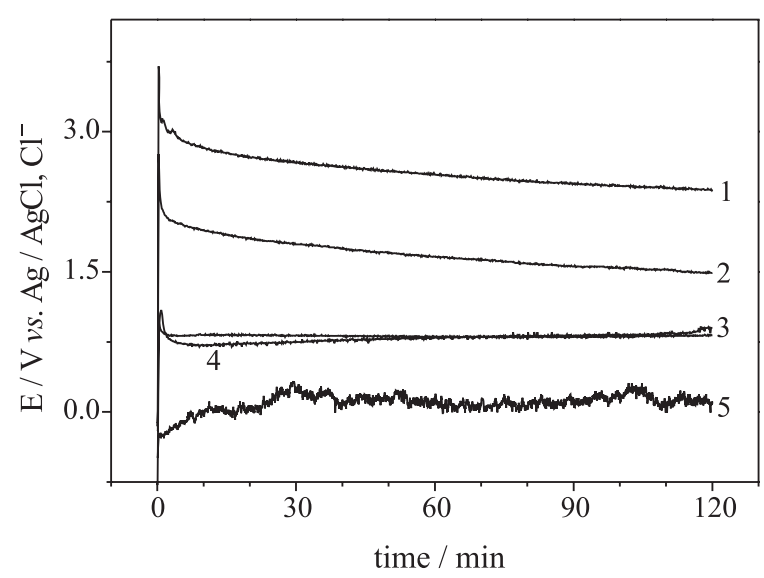

Figure 7. Potential transients for electropolymerization of pyrrole on aluminum electrode from $0.2 \mathrm{~mol} \mathrm{~L}-1$ tartaric acid +0.5 mol L-1 pyrrole, $\mathrm{pH}$ 1.7. The applied current densities $\left(\mathrm{mA} \mathrm{cm}^{-2}\right)$ were: (1) 10 ; (2) 5 ; (3) 2.5 ; (4) 1.0 and (5) 0.5 .

When the applied current density was $0.5 \mathrm{~mA} \mathrm{~cm}^{-2}$, the PPy film formation was visually not observed. In this case, the potential evolves to values below $0.8 \mathrm{~V}$, which is insufficient to perform the pyrrole oxidation. At an applied current density of $1.0 \mathrm{~mA} \mathrm{~cm}^{-2}$, the potential reaches $1.0 \mathrm{~V}$ very quickly $(\sim 50 \mathrm{~s})$, drops to potentials close to $0.70 \mathrm{~V}$ after $300 \mathrm{~s}$, and stabilizes at this potential value. The potential then begins to increase slowly reaching $0.83 \mathrm{~V}$ after $2 \mathrm{~h}$. The PPy film formed in this case is not as homogeneous as that formed at $2.5 \mathrm{~mA} \mathrm{~cm}^{-2}$. In this case, the potential reaches $1.0 \mathrm{~V}$ almost instantaneously (6 s), stabilizes at $0.8 \mathrm{~V}$ after about $100 \mathrm{~s}$, and remains constant at 0.8 $\mathrm{V}$, even after about $2 \mathrm{~h}$ from the moment the current density started to be applied. These results are in accordance with those obtained by cyclic voltammetry. For current densities higher than $2.5 \mathrm{~mA} \mathrm{~cm}^{-2}$, the potential rises almost instantaneously to high positive values and then begin to decrease slowly to potentials values more positive than $0.8 \mathrm{~V}$. For current densities higher than $2.5 \mathrm{~mA} \mathrm{~cm}^{-2}$, besides the PPy electrodeposition, the overoxidation process of polymeric chain might occur.

Adherent and homogeneous films were obtained only when low current densities were applied. Easy peeled off films were formed on the aluminum electrode surfaces when current densities higher than $2.5 \mathrm{~mA} \mathrm{~cm}^{-2}$ were applied. This last phenomenon might be associated with the occurrence of some kind of side reaction, induced by the high current density, which may result in short chain length or lead to formation of defects along the chain. This PPy degradation process was confirmed by SEM micrography and FTIR analyses, which results will be presented in next paragraphs.

\section{Fourier Transform Infrared Red (FTIR) spectra}

FTIR analyses were used to investigate the composition of the PPy films removed from the aluminum surfaces. The PPy films were formed from $0.2 \mathrm{~mol} \mathrm{~L}^{-1}$ tartaric acid $+0.5 \mathrm{~mol} \mathrm{~L}^{-1}$ pyrrole containing aqueous solutions, $\mathrm{pH}$ 1.7 , by cyclic voltammetry (B), varying the potential from -1.0 to $+2.0 \mathrm{~V}$ and back to $-1.0 \mathrm{~V}$ at a sweep rate of $5 \mathrm{mV}$ $\mathrm{s}^{-1}$, and galvanostatically at (C) 2.5 and (D) $10 \mathrm{~mA} \mathrm{~cm}$. Figure 8 shows the FTIR spectra for the films formed during these experiments. The results were compared with those existent in literature, which allowed to do the attributions shown in Table 2. ${ }^{41-46}$

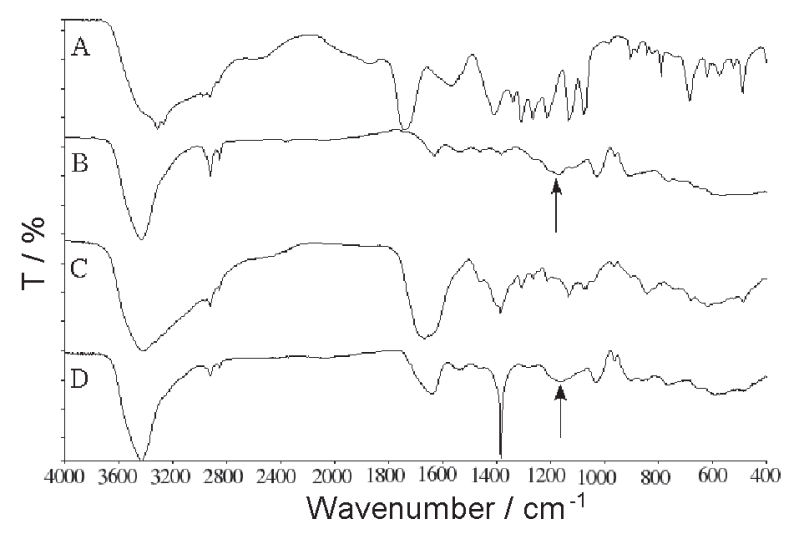

Figure 8. FTIR spectra of: tartaric acid (A) and PPy films electrodeposited from aqueous solutions containing $0.2 \mathrm{~mol} \mathrm{~L}^{-1}$ tartaric acid $+0.5 \mathrm{~mol}$ $\mathrm{L}^{-1}$ pyrrole by: (B) cyclic voltammetry at $5 \mathrm{mV} \mathrm{s}^{-1}$; galvanostatically at (C) 2.5 and (D) $10 \mathrm{~mA} \mathrm{~cm}^{-2}$. 
Table 2. Attributions for PPy films and tartaric acid in the FTIR spectra*

\begin{tabular}{|c|c|c|c|c|c|}
\hline Assignments & Reference & $\operatorname{Tartaric} \operatorname{acid}(\mathrm{A}) / \mathrm{cm}^{-1}$ & $\mathrm{PPy}(\mathrm{B}) / \mathrm{cm}^{-1}$ & $\mathrm{PPy}(\mathrm{C}) / \mathrm{cm}^{-1}$ & PPy (D) $/ \mathrm{cm}^{-1}$ \\
\hline $\mathrm{N}-\mathrm{H}$ str. & {$[42]$} & & 3437 vs & 3424 vs & 3425 vs \\
\hline \multirow[t]{2}{*}{ C-H str. } & {$[42]$} & & $2923 \mathrm{w}$ & $2925 \mathrm{w}$ & 2922 w \\
\hline & & & $2852 \mathrm{w}$ & $2854 \mathrm{w}$ & $2853 \mathrm{w}$ \\
\hline $\mathrm{C}=\mathrm{O}$ str. & {$[22,43,44]$} & $1740 \mathrm{~s}$ & & & \\
\hline Asymmetric carboxylic group str. & {$[43,44]$} & $1568 \mathrm{~m}$ & - & $1670 \mathrm{~s}$ & - \\
\hline \multirow[t]{2}{*}{$\mathrm{C}=\mathrm{C}$ str. } & {$[42,45]$} & - & $1541 \mathrm{w}$ & $1540 \mathrm{w}$ & $1540 \mathrm{w}$ \\
\hline & & - & $1461 \mathrm{w}$ & $1457 \mathrm{w}$ & $1457 \mathrm{w}$ \\
\hline \multirow[t]{2}{*}{ Symmetric carboxylic group str. } & {$[43,44]$} & $1411 \mathrm{~s}$ & - & $1400 \mathrm{sh}$ & - \\
\hline & & $1309 \mathrm{~m}$ & - & $1308 \mathrm{~m}$ & - \\
\hline C-C str. and C-N str. & {$[42,45]$} & - & $1384 \mathrm{w}$ & $1384 \mathrm{~s}$ & $1384 \mathrm{~s}$ \\
\hline \multirow{2}{*}{ C-O str. } & {$[43,44]$} & $1266 \mathrm{~m}$ & - & $1264 \mathrm{w}$ & - \\
\hline & & $1214 \mathrm{~m}$ & - & $1213 \mathrm{w}$ & - \\
\hline $\begin{array}{l}\text { Bipolaron (an electronic state of } \\
\text { the overoxidized polymer) }\end{array}$ & {$[46]$} & - & $1171 \mathrm{~m}$ & - & $1163 \mathrm{~m}$ \\
\hline \multicolumn{6}{|l|}{$\mathrm{C}=\mathrm{O}$ str. } \\
\hline carbonyl str. (on polymer overoxidized) & {$[46]$} & - & $1633 \mathrm{~s}$ & - & $1638 \mathrm{~s}$ \\
\hline Hydroxyl groups def. of tartrate & {$[43,44]$} & $1133 \mathrm{~m}$ & $1133 \mathrm{sh}$ & $1134 \mathrm{~m}$ & $1130 \mathrm{sh}$ \\
\hline $\mathrm{N}-\mathrm{H}$ def & {$[45]$} & & $1033 \mathrm{~m}$ & 1033 w & $1033 \mathrm{~m}$ \\
\hline C-H out-of-plane def. & {$[42]$} & & $962 \mathrm{w}$ & $966 \mathrm{w}$ & $963 \mathrm{w}$ \\
\hline
\end{tabular}

* Intensity of the bands: vs = very strong; s = strong; $\mathrm{m}=$ medium; $\mathrm{w}=$ weak; $\mathrm{sh}=$ shoulder.

The absorption bands at 1171 and $1163 \mathrm{~cm}^{-1}$ in the FTIR spectra of PPy films electrodeposited by (B) cyclic voltammetry and (D) galvanostatically at $10 \mathrm{~mA} \mathrm{~cm}^{-2}$ have been assigned to the bipolaronic species that are formed in the overoxidation process of the PPy. ${ }^{46}$ These spectra also present bands at 1630 that can be attributed at carbonyl groups formed by overoxidation, an irreversible degradation process of the polymeric chain. ${ }^{47-49}$

The displacement of the band at $1740 \mathrm{~cm}^{-1}$, in the tartaric acid FTIR spectrum, to smaller wavenumber (1670 $\mathrm{cm}^{-1}$ ), in the FTIR spectrum of films deposited galvanostatically at $2.5 \mathrm{~mA} \mathrm{~cm}^{-2}$, indicates that the tartaric acid should be incorporated in the film as a dopant and that the doping process might happen through the carboxylic groups.

\section{Morphology of the PPy films, SEM micrographs}

The morphology of aluminum surfaces coated with PPy films was studied by SEM. The polymeric films were deposited on aluminum electrodes from $0.2 \mathrm{~mol} \mathrm{~L}^{-1}$ tartaric

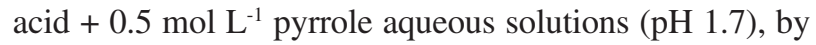
cyclic voltammetry at a sweep rate of $5 \mathrm{mV} \mathrm{s}^{-1}$, and galvanostatically at 2.5 and $10 \mathrm{~mA} \mathrm{~cm}{ }^{-2}$. Figure 9 shows these micrographs.

Films formed potentiodynamicallycally are much less uniform than films formed galvanostatically. Films formed galvanostatically are more homogeneous presenting a cauliflower-like structure constituted by micro-spherical grains. It has been reported that this cauliflower structure is related to the dopant intercalation difficulty in the
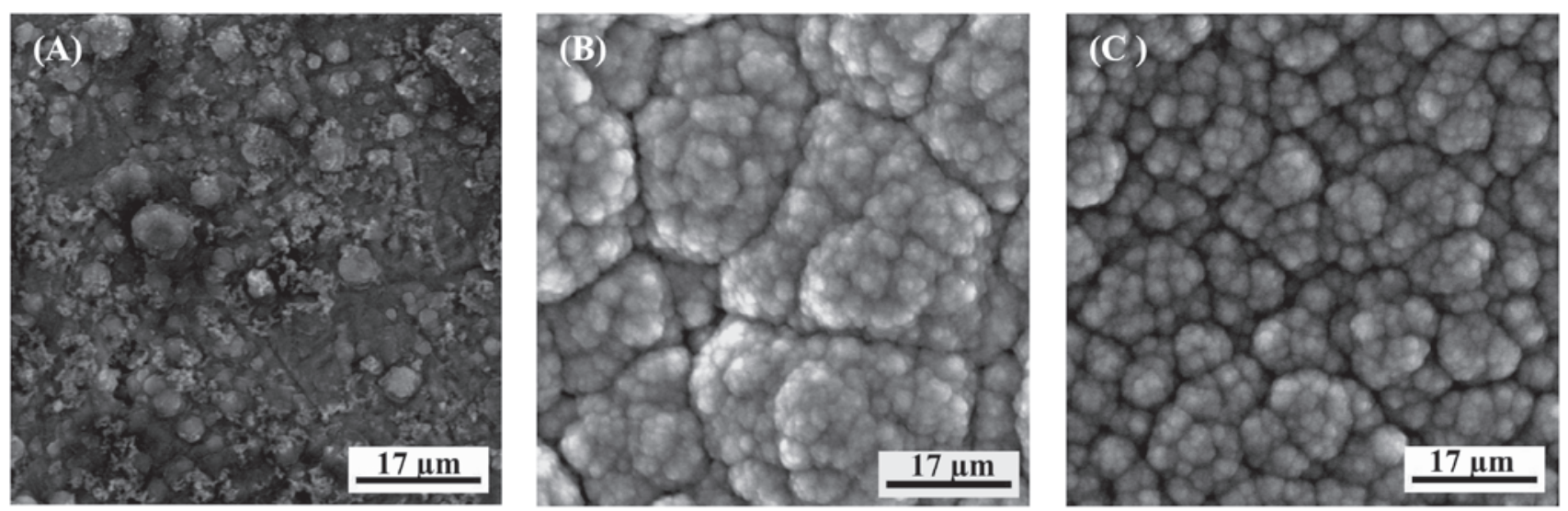

Figure 9. SEM of aluminum surfaces coated with PPy films electrodeposited from solutions containing $0.2 \mathrm{~mol} \mathrm{~L}^{-1}$ tartaric acid +0.5 mol L-1 pyrrole: (A) potentiodynamically at $5 \mathrm{mV} \mathrm{s}^{-1}$; galvanostatically at (B) 2.5 and (C) $10 \mathrm{~mA} \mathrm{~cm}$. 
disordered polymeric chain. ${ }^{26}$ PPy films formed at higher current densities $\left(10 \mathrm{~mA} \mathrm{~cm}^{-2}\right)$ present smaller cauliflowers size, with larger voids among them, than films formed at lower current density values (e.g., $2.5 \mathrm{~mA} \mathrm{~cm}^{-2}$ ). The same explanation given previously to justify the poor adherence of films formed at high current density can be used to explain the morphology differences between films formed at low and high currents densities. Films formed at high current density $\left(10 \mathrm{~mA} \mathrm{~cm}{ }^{-2}\right)$ were more susceptible to overoxidation processes, which result in a short chain length, and/or leads to formation of defects along the chain, resulting in a less protective film. Such suggestions were demonstrated by the higher performance of films formed at $2.5 \mathrm{~mA} \mathrm{~cm}^{-2}$ to protect aluminum surfaces against corrosion.

\section{Corrosion tests}

The behaviour of aluminum surfaces coated with PPy films was investigated in chloride containing medium, to characterize the corrosion protection afforded by such films.

Figure 10 shows the potentiodynamic polarization curves, in $0.1 \mathrm{~mol} \mathrm{~L}^{-1} \mathrm{NaCl}$ aqueous solution, $\mathrm{pH} \mathrm{5.9,} \mathrm{for}$ the polished aluminum surfaces and for aluminum surfaces coated with PPy films deposited galvanostatically at 2.5 and $10 \mathrm{~mA} \mathrm{~cm}^{-2}$ using the same deposition charge. The electrochemical parameters obtained from the polarization curves (Figure 10) are presented in Table 3. The $\mathrm{E}_{\text {corr }}$ and $\mathrm{j}_{\text {corr }}$ values for aluminum surfaces coated with PPy films deposited by cyclic voltammetry at $5 \mathrm{mV} \mathrm{cm}^{-2}$ are also presented in Table 3.

The corrosion potential of surfaces coated with PPy films shifted to less negative values and the anodic current densities of these surfaces were smaller than those presented for just polished aluminum surfaces.

It was also observed that the corrosion protection afforded by the PPy films electrodeposited galvanostatically depend on the applied current density. Films formed at 2.5 $\mathrm{mA} \mathrm{cm}{ }^{-2}$ offer a better corrosion protection to the aluminum surfaces than films electrodeposited at $10.0 \mathrm{~mA} \mathrm{~cm}{ }^{-2}$. This

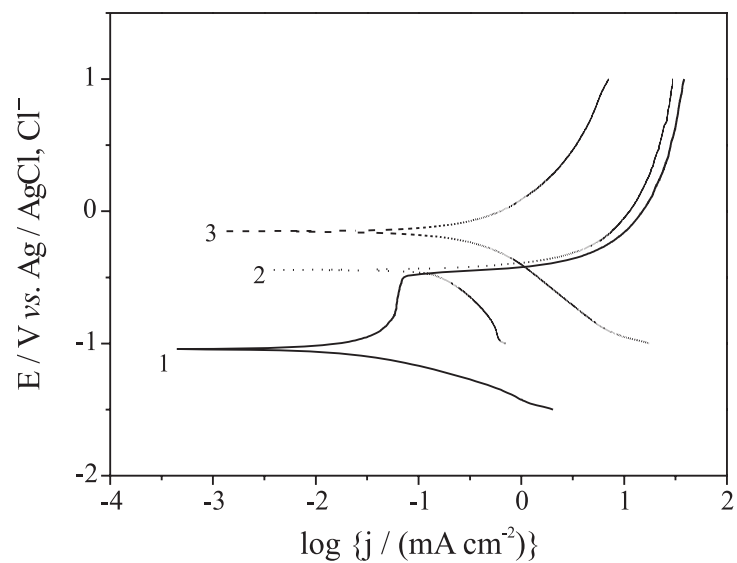

Figure 10. Polarization curves, at $5 \mathrm{mV} \mathrm{s}^{-1}$, in $0.1 \mathrm{~mol} \mathrm{~L}^{-1} \mathrm{NaCl}$ aqueous solution (pH 5.9), for aluminum surface: (1) only polished; coated with PPy deposited galvanostatically at (3) 2.5 and (2) $10 \mathrm{~mA} \mathrm{~cm}$.

observation was demonstrated by the lower anodic current densities presented for surfaces coated with PPy films electrodeposited at $2.5 \mathrm{~mA} \mathrm{~cm}^{-2}$ (Figure 10, curve 3). This result was attributed to the better homogeneity of these films, which was also indicated by the SEM analyses (Figure 9B). The presence of the voids among the cauliflowerstructure in films galvanostatically electrodeposited at 10.0 $\mathrm{mA} \mathrm{cm}{ }^{-2}$ (Figure 9C) allows the penetration of chloride ions (aggressive species) favoring the corrosion process.

The cathodic current densities were higher for the aluminum surfaces coated with PPy than for the uncoated surfaces. Similar results have been shown in literature. ${ }^{50,51}$ Furthermore, it was observed that surfaces coated with films galvanostatically deposited at $2.5 \mathrm{~mA} \mathrm{~cm}^{-2}$ presented higher cathodic current densities than those coated with films deposited potentiodynamically or galvanostatically at $10 \mathrm{~mA} \mathrm{~cm}{ }^{-2}$. These results were ascribed to a smaller overoxidation degree, an irreversible process, of the films deposited at $2.5 \mathrm{~mA} \mathrm{~cm}^{-2}$. PPy matrixes with smaller overoxidation degree are more conductive. Thus, they are more prone to reduction reactions than matrixes subjected to a higher overoxidation degree.

The possible chemical reactions occurring onto aluminum surfaces coated by PPy during the polarizations experiments are represented bellow. ${ }^{15}$

Table 3. Electrochemical parameters obtained for just polished and for aluminum coated with PPy films exposed to a $0.1 \mathrm{~mol} \mathrm{~L}^{-1} \mathrm{NaCl}$ aqueous solutions, open to air

\begin{tabular}{lcc}
\hline Polished Aluminum Surfaces & $\mathrm{E}_{\text {corr }} /(\mathrm{V} . v s . \mathrm{Ag}, \mathrm{AgCl})$ & $\mathrm{j}_{\mathrm{corr}} /\left(\mathrm{mA} \mathrm{cm}^{-2}\right)$ \\
\hline $\begin{array}{c}\text { Uncoated (just polished surfaces) } \\
\text { Coated with PPy deposited galvanostatically at }\end{array}$ & -1.03 & 0.023 \\
$2.5 \mathrm{~mA} \mathrm{~cm}^{-2}$ & -0.16 & 0.37 \\
$10.0 \mathrm{~mA} \mathrm{~cm}^{-2}$ & -0.44 & 0.25 \\
Coated with PPy deposited potentiodynamically at & & 0.26 \\
\hline $\mathrm{mV} \mathrm{s}^{-1}$ & -0.45 & 0.26 \\
\hline
\end{tabular}


Anodic reactions

$\mathrm{Al} \rightarrow \mathrm{Al}^{+3}+3 \mathrm{e}^{-}$

Overoxidation of polymer

$\mathrm{PPy}_{\text {undopaded }} \rightarrow \mathrm{PPy}_{\text {dopaded }}+\mathrm{ne}^{-}$

Cathodic reactions

$2 \mathrm{H}_{2} \mathrm{O}+\mathrm{O}_{2}+4 \mathrm{e}^{-} \rightarrow 4 \mathrm{OH}^{-}$

$\mathrm{PPy}_{\text {dopaded }}+\mathrm{ne}^{-} \rightarrow \mathrm{PPy}_{\text {undopaded }}$

A higher overoxidation degree of the PPy films formed potentiodynamically and galvanostatically at $10.0 \mathrm{~mA} \mathrm{~cm}$, would explain the lower cathodic current densities observed for aluminum surfaces coated with these films. A bigger contribution of polymeric matrix reduction reactions during the polarization experiments of the aluminum surfaces coated with PPy films formed at 2.5 $\mathrm{mA} \mathrm{cm}^{-2}$, which have a smaller overoxidation degree, justifies the higher current densities observed for these surfaces, and, consequently, their higher corrosion current density values.

The results presented in this paper differ from those showed in the literature, on which aluminum surfaces coated with PPy films electrodeposited from a saccharin containing medium presented corrosion current densities lower than uncoated aluminum surfaces. ${ }^{52}$ This difference can be associated to the overoxidation and doping degree of PPy films electrodeposited on different electrolytes.

\section{Conclusions}

The PPy film growth in aqueous solution containing pyrrole and tartrate species can be explained by a mechanism, which considers the formation of conducting paths of PPy through a porous aluminum oxide layer produced during the PPy electropolymerization process. The more homogeneous the distribution of pores on this aluminum oxide layer, the smaller the resistance offered to the PPy film growth. The pore distribution on the oxide layer depends on the concentration of tartaric acid and, consequently, the PPy electrodeposition process also depends on the tartaric acid concentration in aqueous solution. The electropolymerization process also depends on synthesis parameters, such as pyrrole concentration, solution $\mathrm{pH}$ and applied current density.

Films galvanostatically deposited at higher current densities are more susceptible to the overoxidation process than films formed at lower current densities. These results were demonstrated in the SEM micrographs by smaller size of the cauliflower-structures, with larger voids among them when the films were formed at $10 \mathrm{~mA} \mathrm{~cm}^{-2}$ than films deposited at lower current density values. Such observation was also demonstrated by the FTIR results.

Independent of the electrodeposition method, all aluminum surfaces coated with PPy films presented corrosion current densities higher than uncoated aluminum surfaces. However, if the anodic current densities observed in the potentiodynamic corrosion experiments are used as a criterion to measure the corrosion protection afforded by the PPy films, it would be possible to affirm that aluminum surfaces coated with the polymeric films are less susceptible to corrosion processes than just polished ones, and that PPy films electrodeposited galvanostatically at lower current densities offer better corrosion protection to the aluminum surfaces than those electrodeposited by cyclic voltammetry or galvanostatically using higher values of current densities.

\section{Acknowledgments}

The authors thank the Fundação de Amparo à Pesquisa do Estado de São Paulo (FAPESP) for the support given to the Process No 2001/02745-6 and the Alcoa Alumínio SA, São Luis, Maranhão, Brazil.

\section{References}

1. Ingram, M. D.; Staesche, H.; Ryder, K. S.; Solid State Ionics 2004, 169, 51.

2. Ameer, Q.; Adeloju, S. B.; Sens. Actuators, B 2005, 106, 541.

3. Tallman, D. E.; Sokins, G.; Dominis, A.; Wallace, G. G.; J. Solid State Electrochem. 2002, 6, 73.

4. Malinauskas, A.; Polymer 2001, 42, 3957.

5. Herrasti, P.; Ocon, P.; Appl. Surf. Sci. 2001, 172, 276.

6. Paloumpa, I.; Yfantis, A.; Hoffmann, P.; Burkov, Y.; Tfantis, D.; Schmeiber, D.; Surf. Coat. Technol. 2004, 180, 308.

7. Champagne, S. D.; Duchet, J.; Legras, R.; Synth. Met. 1999, 101, 20.

8. Wang, L. X.; Li, X. G.; Yang, Y. L.; React. Funct. Polym. 2001, 47, 125.

9. Ayad, M. M.; Polym. Int. 1994, 35, 35.

10. Wencheng, S.; Iroh, J. O.; Synth. Met. 1998, 95, 159.

11. Deronzier, A.; Moutet, J. C.; Current Topics Electrochem. 1994, 3, 159 .

12. Ferreira, C. A.; Aeiyach, S.; Aaron, J. J.; Lacaze, P. C.; Electrochim. Acta 1996, 41, 1801.

13. Wencheng, S.; Iroh, J. O.; Electrochim. Acta 2000, 46, 1.

14. Le, H. N. T.; Garcia, B.; Deslouis, C.; Xuan, Q. L.; Electrochim. Acta 2001, 46, 4259.

15. Ocon, P.; Cristobal, A.B.; Herrasti, P.; Fatas, E.; Corros. Sci. 2005, 47, 649.

16. Tuken, T.; Surf. Coat. Technol. 2006, 200, 4713. 
17. Santos, L. M. M.; Lacroix, J. C.; Ching, K. I. C.; Adenir, A.; Abrantes, L. M.; Lacaze, P. C.; J. Electroanal. Chem. 2006, $587,67$.

18. Cacalheira, A. C.; Aeiyach, S.; Lacaze, P. C.; Abrantes, L. M.; Electrochim. Acta 2003, 48, 2523.

19. Hulser, P.; Beck, F.; J. Electrochem. Soc. 1990, 137, 2067.

20. Hulser, P.; Beck, F.; J. Appl. Electrochem. 1990, 20, 596.

21. Naoi, K.; Takeda, M.; Kanno, H.; Sakakura, M.; Shimada, A.; Electrochim. Acta 2000, 45, 3413.

22. Akundy, G. S.; Iroh, J. O.; Polymer 2001, 42, 9665.

23. Saidman, S. B.; Bessone, J. B.; J. Electroanal. Chem. 2002. $521,87$.

24. Tallman, D. E.; Dewald, M. P.; Vang, C. K.; Wallace, G. G.; Bierwagen, G. P.; Curr. Appl. Phys. 2004, 4, 37.

25. Tsai, M. L.; Chen, P. J.; Do, J. S.; J. Power Sources 2004, 133, 302.

26. Bazzaoui, M.; Martins, L.; Bazzaoui, E. A.; Martins, J. I.; Electrochim. Acta 2002, 47, 2953.

27. Bazzaoui, M.; Martins, L.; Bazzaoui, E. A.; Martins, J. I.; J. Electroanal. Chem. 2002, 537, 47.

28. Petijean, J.; Tanguy, J.; Lacroix, J. C.; Chane-Ching, K. I.; Aieyach, S.; Delamar, M.; Lacaze, P. C.; J. Electroanal. Chem. 2005, 581, 111.

29. Norma ASTM G 102-89, Practice for Calculation of Corrosion Rates and Related Information from Electrochemical Measurements, 1994

30. Lee, W. J.; Pyun, S. I.; Electrochim. Acta 1999, 44, 4041.

31. McCafferty, E.; Corros. Sci. 1995, 37, 481.

32. Mazhar, A. A.; Arab, S. T.; Noor, E. A.; Bull. Electrochem. 2001, 17, 449.

33. Snizhko, L. O.; Yeroklin, A.L.; Gurevina, N. L.; Misnyankin, A. L.; Pilkington, A.; Leyland, A.; Mattwes, A. Electrochim. Acta 2005, 50, 5458.

34. Moon, S. M.; Pyun, S. I.; Electrochim. Acta 1999, 44, 2445.
35. Desroches, S.; Daydé, S.; Berthon, G.; J. Inorg. Biochem. 2000, $81,301$.

36. Adb El Aal, E.E.; Corros. Sci. 2003, 45, 759.

37. Wilhelmsen, W.; Arnese, T.; Hasvold, O.; Storkersen, N.; Electrochim. Acta 1991, 36, 79.

38. Moshier, C.; Davis, G. D.; Ahearn, J. S.; Corros. Sci. 1987, 27, 785.

39. Fernández, I.; Trueba, M.; Núnez, C. A.; Rieumont, J.; Surf. Coat. Technol. 2005, 191, 134.

40. Saidman, S. B.; J. Electroanal. Chem. 2002, 534, 39.

41. Saidman, S. B.; Vela, M. E.; Thin Solid Films 2005, 493, 96.

42. Tian, B.; Zerbi, G.; J. Chem. Phys. 1990, 92, 3886.

43. Marchewka, M. K.; Debrus, S.; Pietraszko, A.; Barnes, A. J.; Ratajczak, H.; J. Mol. Struct. 2003, 656, 265.

44. Hon, Y. M.; Fung, K. Z.; Lin, S. P.; Hon, M. H.; J. Solid State Chem. 2002, 163, 231.

45. Jang, K. S.; Lee, H.; Moon, B.; Synth. Met. 2004, 143, 289.

46. Rodriguez, I.; Scharifker, B. R.; Mostany, J.; J. Electroanal. Chem. 2000, 491, 117.

47. Li, Y.; Qian, R.; Electrochim. Acta 2000, 45, 1727.

48. Mazeikien, R.; Malinauskas, A.; Polym. Degrad. Stab. 2002, $75,255$.

49. Fabre, B.; Chayer, S.; Vicent, M.G. H.; Electrochem. Commun. 2003, 5, 431 .

50. Vilca, D. H.; Moraes, S. R.; Motheo, A. J.; Synth. Met. 2004, 140, 23.

51. Breslin, C.B.; Fenelon, A. M.; Conroy, K. G.; Materials and Design 2005, 26, 233.

52. Bazzaoui, M.; Martins, J. I.; Costa, S. C.; Bazzaoui, E. A.; Reis, T. C.; Martins, L.; Electrochim. Acta 2006, 51, 2417.

Received: April 19, 2006 Web Release Date: January 19, 2007

FAPESP helped in meeting the publication costs of this article. 